\title{
Anthocyanin-rich extracts from purple and red potatoes as natural colourants: Bioactive properties, application in a soft drink formulation and sensory analysis
}

\author{
Shirley L. Sampaio ${ }^{\mathrm{a}, \mathrm{e}}$, Julien Lonchamp ${ }^{\mathrm{b}}$, Maria Inês Dias ${ }^{\mathrm{a}, *}$, Catriona Liddle ${ }^{\mathrm{b}}$, \\ Spyridon A. Petropoulos ${ }^{c}$, Jasmina Glamočlija ${ }^{\mathrm{d}}$, Alexios Alexopoulos ${ }^{\mathrm{e}}$, \\ Celestino Santos-Buelga ${ }^{\text {f,g }}$, Isabel C.F.R. Ferreira ${ }^{a}$, Lillian Barros ${ }^{\text {a, * }}$

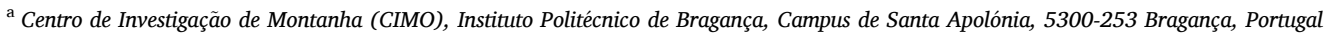 \\ b School of Health Sciences, Queen Margaret University, Queen Margaret University Drive, Edinburgh EH21 6UU, United Kingdom

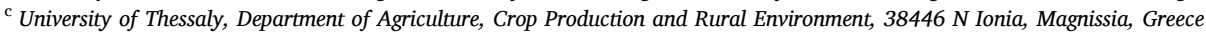 \\ d Institute for Biological Research "Siniša Stanković", National Institute of Republic of Serbia, University of Belgrade, Serbia \\ ${ }^{\mathrm{e}}$ University of the Peloponnese, Department of Agriculture, 24100 Kalamata, Greece \\ ${ }^{\mathrm{f}}$ Grupo de Investigación en Polifenoles (GIP-USAL), Facultad de Farmacia, Universidad de Salamanca, Campus Miguel de Unamuno s/n, 37007 Salamanca, Spain \\ ${ }^{\mathrm{g}}$ Unidad de Excelencia Producción, Agrícola y Medioambiente (AGRIENVIRONMENT), Parque científico, Universidad de Salamanca, 37185 Salamanca, Spain
}

\section{A R T I C L E I N F O}

\section{Keywords:}

Natural colourants

Coloured potatoes

Anthocyanins

Bioactivities

Sensory analysis

Solanum tuberosum L

\begin{abstract}
A B S T R A C T
Aqueous extracts from seven coloured potato varieties (three red-fleshed, three-purple fleshed, and one marblefleshed) were studied for their anthocyanin content, in vitro biological activities, colouring properties and their potential application in the food industry. Acylated glycosides or pelargonidin and petunidin aglycones were identified as the main anthocyanin forms in the red and purple varieties, respectively. The total anthocyanin content among varieties ranged from 478.3 to $886.2 \mathrm{mg} / 100 \mathrm{~g}$ extract. All the extracts presented in vitro antioxidant, antibacterial and antifungal activities, whereas no toxic effects were detected. Finally, two selected extracts were tested as colourants in a soft drink formulation and presented suitable sensory profiles as well as high colour stability during a 30-day shelf-life when compared with the commercial colourant E163. Therefore, the tested extracts could be used as natural food colourants and considered for substituting the existing synthetic colouring agents.
\end{abstract}

\section{Introduction}

There is a growing interest worldwide in the development of food colourants from natural sources as a consequence of perceived consumer preferences and the concerns about the use of synthetic compounds in food products (Albuquerque, Pinela, Barros, Oliveira, \& Ferreira, 2020; Petropoulos et al., 2019). In response to that, the food and beverage industries have been seeking natural colouring agents that could substitute synthetic dyes and colouring additives and increase the beneficial health effects of the final product due to their high content in bioactive compounds (Petropoulos et al., 2019; Sampaio et al., 2020b; Schieber, Stintzing, \& Carle, 2002).

Coloured root vegetable products can be alternative sources of colouring and bioactive compounds (Hossain, Rawson, Aguiló-Aguayo,
Brunton, \& Rai, 2015; Nemś \& Pęksa, 2018). Among root vegetables, potato (Solanum tuberosum L.) is the most consumed worldwide, being a staple for 1.3 billion people and with an increasing popularity in the developing world (Stokstad, 2019). This nutritious vegetable also presents the highest genetic diversity among all cultivated species, with approximately 5000 registered varieties and a broad phenological variation in terms of flesh and skin colour (Petropoulos et al., 2019). Red and purple-fleshed potatoes are rich in phenolic compounds, particularly in anthocyanins, presenting about three times higher amounts of total phenolic compounds content than the widely consumed white- and yellow-fleshed tubers, as well as two to three times higher antioxidant activity (Petropoulos et al., 2019). Anthocyanins are suitable to be used as natural colouring compounds due to their bright attractive red and purple colours and water solubility that allows for their easy

\footnotetext{
* Corresponding authors.

E-mail addresses: maria.ines@ipb.pt (M.I. Dias), lillian@ipb.pt (L. Barros).
} 
incorporation into aqueous food systems (Rodriguez-Saona, Giusti, \& Wrolstad, 2008; Rodríguez-Saona, Glusti, \& Wrolstad, 1999). Nevertheless, their use can pose problems of colour instability when they are out of their natural environment, as affected by factors such as $\mathrm{pH}$, temperature, light and oxygen or interactions with other coexisting components, among others (Santos-Buelga \& González-Paramás, 2019). The anthocyanin molecules found in coloured potatoes are usually acylated with p-coumaric or ferulic acids. The acylation of the anthocyanin molecules improves pigment stability during processing and storage (Rodriguez-Saona, GiustiI, \& Wrolstad, 1998). This effect is chemically explained by the stacking of the acyl groups with the pyrylium ring of the flavylium cation, which reduces the susceptibility of the nucleophile attack of water on the hydrophilic anthocyanin molecules and the formation of a colourless pseudobase and light yellow chalcone forms (Sasaki, Nishizaki, Ozeki, \& Miyahara, 2014; Santos-Buelga \& González-Paramás, 2019).

Natural anthocyanins have powerful colouring capacities and at acidic $\mathrm{pH}$ values only small concentrations of these compounds are required to obtain the desired red, pink and purple colours in food products (Mateus \& Freitas, 2009). Moreover, these compounds are associated with several health effects that could improve the overall quality of the final product, while they could allow the design of new functional and natural products that are highly appreciated by the market (Quan et al., 2019; Wrolstad \& Culver, 2012). The list of applications of anthocyanins as colouring agents is long, comprising products such as fruit preservatives (Bursać Kovačević et al., 2015), sugar confectionary (Mateus \& Freitas, 2009), dairy products (Montibeller, de Lima Monteiro, Tupuna-Yerovi, Rios, \& Manfroi, 2018; Pires et al., 2018), dry mixes (acid dessert mixes and drink powders) (Mateus \& Freitas, 2009), frozen products (ice creams) (Mateus \& Freitas, 2009), bakery products (Albuquerque et al., 2020; Da Silva et al., 2019a; Da Silva et al., 2019b) and beverages (Monteiro et al., 2017; Montibeller et al., 2018). Among all possible applications, soft drinks are suitable candidates due to their acidic $\mathrm{pH}$ (below 3.5) and the high solubility of anthocyanins in water (Mateus \& Freitas, 2009; Montibeller et al., 2018). Nevertheless, these molecules can be affected by heat processing, hence the importance of testing the colour stability after pasteurisation, since soft drink formulations are usually heat-processed to prolong the product's shelf-life and increase their safety.

In this work we present an in-depth characterisation of the anthocyanin profile and the bioactivities (in vitro antioxidant, antibacterial and antifungal activities) of aqueous extracts from six varieties of red and purple-fleshed potatoes, as well as a marble-fleshed cultivar being used for comparison purposes. Furthermore, a cytotoxicity assay to test the safety of the extracts was carried out, and then two varieties (one red and one purple) that presented the most promising results were selected for an application study by incorporating their extracts in a pasteurised soft drink model. Moreover, considering the current market trends and consumer preferences for food products free of synthetic compounds we aimed at evaluating the potential use of the tested extracts as natural colouring agents in commercial products. Therefore, the sensory profile of the pasteurised soft drink was assessed by quantitative descriptive analysis (QDA) and the colour stability of the products was monitored over a 30-day shelf-life period, comparing the performance of the extracts with the commercial colourant E163.

\section{Materials and methods}

\subsection{Plant material}

Twenty potato seeds (tubers) from the tested potato varieties (Solanum tuberosum L.), namely three red-fleshed genotypes (cv. Rosemary, Red Emmalie, and Red Cardinal), three purple-fleshed genotypes (cv. Purple, Violetta, and Kefermarkter Blaue), and one marble-fleshed genotype (cv. Shetland Black) were purchased from the Leibniz Institute of Plant Genetics and Crop Plant Research (IPK). The obtained tubers were cultivated in the experimental farm of the University of Thessaly in Velestino, Greece, according to commercial cultivation protocols during the spring-summer growing period of 2018. Seed tubers were planted manually on 3/4/2018 with distances of $75 \mathrm{~cm}$ between hills and $30 \mathrm{~cm}$ within each hill and approximately $10 \mathrm{~cm}$ depth (Petropoulos et al., 2020). Fertilizers were applied with base-dressing (400 kg/ha of 15-15-15 (N-P-K fertilizer) and two side-dressings (1st: $50 \mathrm{~kg} / \mathrm{ha}$ of ammonium nitrate; 2 nd $50 \mathrm{~kg} / \mathrm{ha}$ of potassium nitrate). Irrigation was applied via a sprinkler irrigation system, while weeds and pests were controlled according to the best practice guides for the crop. Tubers were harvested manually on $27 / 7 / 2018$. The fresh harvested tubers (Fig. 1) were transported to the Polytechnic Institute of Bragança, Portugal, where the samples were washed with cold water upon arrival to eliminate extraneous matter and refrigerated at $4{ }^{\circ} \mathrm{C}$ until analysis.

\subsection{Extracts preparation}

Washed potato tubers were manually peeled and immediately immersed in an aqueous citric acid solution $(0.5 \mathrm{~mol} / \mathrm{L})$ to prevent browning ( $1 \mathrm{~g}$ fresh tuber $/ 2 \mathrm{~mL}$ citric acid solution). After the immersion in the citric acid solution, the whole peeled tubers were gently blended (commercial juice blender, Breville Blend Active model VBL134) and filtered twice (Whatman No. 4 paper). The obtained acidified aqueous extracts $(\mathrm{pH} \sim 3)$ were freeze-dried $\left(-49^{\circ} \mathrm{C}, 0.08 \mathrm{bar}\right.$, during 48 h, FreeZone 4.5 model 7750031, Labconco, Kansas, USA). All seven resulting extracts presented a yield of approximately $5 \%$ (mass of freeze-dried extract/mass of whole fresh potato). All steps in the extraction process were carried out in food grade facilities.

\subsection{Determination of anthocyanin content and bioactivities}

\subsubsection{Chromatographic analysis of anthocyanins}

The seven freeze-dried extracts were dissolved in water to a concentration of $50 \mathrm{mg} / \mathrm{mL}$ and filtered through $0.22 \mu \mathrm{m}$ disposable syringe filters into amber vials for high performance liquid chromatography (HPLC) analysis. The analysis was performed using a Dionex Ultimate 3000 HPLC (Thermo Scientific) system equipped with a quaternary pump, an automatic injector (at $5{ }^{\circ} \mathrm{C}$ ), a degasser, and an automated thermostat column compartment. The compounds detection was carried out with a diode-array detector (DAD), using $520 \mathrm{~nm}$ as preferred wavelength, and electrospray ionisation (ESI) coupled to a mass spectrometry (MS) detector (HPLC-DAD-ESI/MS), operating under the conditions described by Albuquerque et al. (2020). Data were collected and analysed using the Xcalibur ${ }^{\circledR}$ program (Thermo Scientific). The identification was performed from the chromatographic retention characteristics and UV-Vis and mass spectra, and comparison with data described in the literature. The quantification was performed using a 7-level calibration curve of peonidin-3-O-glucoside $\left(y=151438 x-3 \mathrm{E}^{+06}\right.$, $R^{2}=0.9977, \mathrm{LOD}=0.20 \mu \mathrm{g} / \mathrm{mL}$ and $\mathrm{LOQ}=0.71 \mu \mathrm{g} / \mathrm{mL}$; Sigma-Aldrich, St. Louis, MO, USA). Results were expressed as mg per $100 \mathrm{~g}$ of extract.

\subsubsection{Antioxidant activity}

The antioxidant activity of the seven extracts was assessed in terms of their potential to inhibit the production of thiobarbituric acid reactive substances (TBARS) in brain homogenates, a cell-based in vitro method previously described by Sampaio et al. (2020a). The formation of the complex malondialdehyde-thiobarbituric acid was measured at $532 \mathrm{~nm}$ and the results expressed as $\mathrm{IC}_{50}$ values $(\mathrm{mg} / \mathrm{mL}$ of extract).

\subsubsection{Cytotoxicity evaluation}

The seven potato extracts were dissolved in water $(4 \mathrm{mg} / \mathrm{mL})$ and submitted to further dilutions. A cell culture (PLP2) was prepared using a freshly harvested porcine liver according to the method described by Corrêa et al. (2015). The sulforhodamine B assay was performed to evaluate any possible cytotoxicity of the extracts. Ellipticine (SigmaAldrich, St. Louis, MO, USA) was employed as a positive control and the 


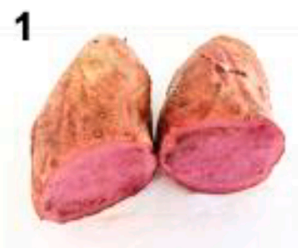

2

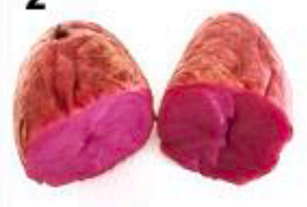

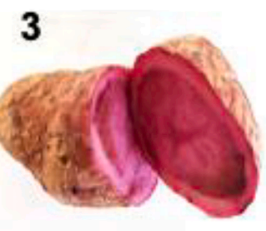

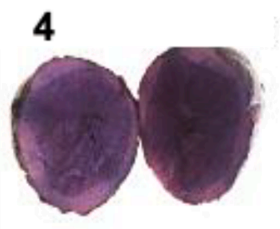

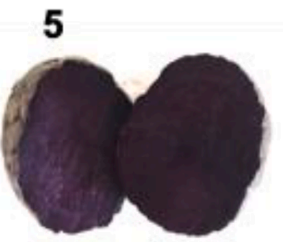

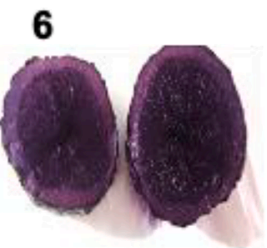

7

a)<smiles>Oc1ccc(-c2[o+]c3cc(O)cc(O)c3cc2O)cc1</smiles>

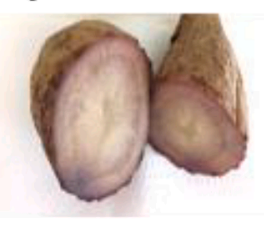

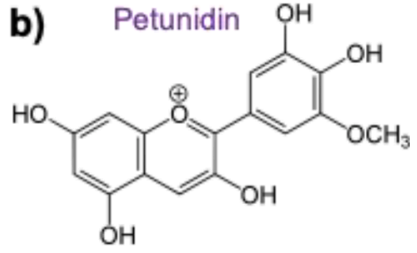

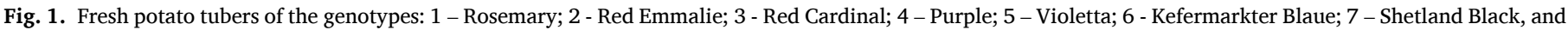

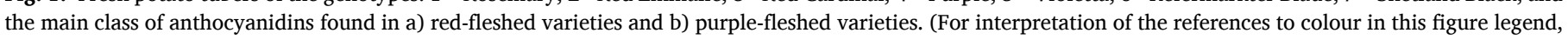
the reader is referred to the web version of this article.)

results were expressed in $\mathrm{GI}_{50}$ values.

\subsubsection{Antibacterial and antifungal activities}

With the aim to assess the potential use of the potato extracts as natural food preservatives, their antibacterial and antifungal activities were evaluated according to the procedure described by Corrêa et al. (2015). Three Gram-positive bacteria (Bacillus cereus (clinical isolate), Staphylococcus aureus (ATCC 11632) and Listeria monocytogenes (NCTC 7973)) and three Gram-negative bacteria (Escherichia coli (ATCC 25922), Enterobacter cloacae (ATCC 35030) and Salmonella Typhimurium (ATCC 13311)) were used to determine the potential antibacterial activity of the extracts. For the antifungal assays, six micromycetes were tested, namely Aspergillus fumigatus (human isolate), Aspergillus versicolor (ATCC11730), Aspergillus niger (ATCC 6275), Penicillium funiculosum (ATCC 36839), Trichoderma viride (IAM 5061) and Penicillium aurantiogriseum (food isolate). Two commercial food preservatives were used as positive controls: potassium metabisulphite (E224) and sodium benzoate (E211). Results were given as minimal inhibitory, bactericidal and fungicidal concentrations (MIC, MBC and MFC, respectively).

\subsection{Validation of the anthocyanin-rich extracts as natural colourants}

\subsubsection{Soft drink formulation}

Following the screening of the seven potato varieties based on their anthocyanin content and bioactive properties, two extracts were selected to be applied as colouring agents in a soft drink formulation: cv. Rosemary (red-flesh potato variety) and cv. Purple (purple-fleshed potato variety). A typical raspberry flavoured soft drink formulation was prepared, composed of sparkling water, caster sugar, citric acid, sucralose and natural flavourings (raspberry and peach), in decreasing order of concentration. Three soft drink formulations were prepared with (1) the red anthocyanin-rich potato extract (Rosemary), (2) the purple anthocyanin-rich potato extract (Purple) and (3) the commercial colorant E163 (standardised in 1\% anthocyanins content). The latter formulation (3) was used as control. The colourants were added to the respective formulations in order to obtain a similar concentration of anthocyanins ( $\sim 8 \mathrm{mg} / \mathrm{L}$ solution), which visually matched the colour intensity of a commercial soft drink product used as reference. The commercial colorant E163 used as control in the soft drink formulations was purchased from Naturex (Derbyshire, UK), consisting of an anthocyanin glucosides' extract derived from grapes and standardised in 1\% of anthocyanins content by the supplier, preserved with potassium sorbate. All soft drink samples were prepared according to good hygiene and manufacturing practices in food grade facilities.

\subsubsection{Pasteurisation}

The three soft drink formulations (Rosemary, Purple and Control) were poured into glass containers $(250 \mathrm{~mL})$, which were sealed and placed in a water bath at $70{ }^{\circ} \mathrm{C}$ for $20 \mathrm{~min}$, following the in-pack pasteurisation method described by Ashurst (2011).

\subsubsection{Colour stability and determination of $\mathrm{pH}$}

Following pasteurisation, the three soft drink formulations (Rosemary, Purple and Control) were stored at $4{ }^{\circ} \mathrm{C}$ and their colour stability was assessed at 0,7 and 30 days of storage. A PCE colourimeter (model CSM-3; PCE Instruments, Germany) was used to measure the colour by placing $80 \mathrm{~mL}$ of each formulation in a quartz glass box designed for measurements carried out on liquid samples. Using a silicon photoelectric diode sensor and a measuring aperture of $8 \mathrm{~mm}$, the following CIELab colour space readings were measured through the computerized system: $L^{*}$ : lightness from black (0) to white (100); $a^{*}$ : green ( - ) to red $(+) ; b^{*}$ : blue $(-)$ to yellow $(+) ; \mathrm{C}^{*}$ : chroma, relative saturation; and $\mathrm{h}^{\circ}$ : hue angle in the CIELab colour wheel.

The $\mathrm{pH}$ of the formulated soft drinks was measured using a calibrated digital pH meter (portable food and dairy pH meter HI 99161, Hanna Instruments, Woonsocket, RI, USA). All pH measurements were carried out in triplicate. All three soft drink formulations presented a final $\mathrm{pH}$ of approximately 3 .

\subsubsection{Sensory analysis}

A sensory analysis was carried out immediately after the soft drinks' production and pasteurisation (Day 0). Sessions took place in the sensory suite facility of the Scottish Centre for Food Development and Innovation (SCFDI) at Queen Margaret University (Edinburgh, UK). The test panel participants were informed about the general aim of the study and the required procedures for handling personal data. All participants gave written informed consent prior to participation. Twelve experienced trained panellists were selected and subsequently received specific additional training on the sensory attributes relevant to the soft drink formulation developed in this project using a range of commercial products. Sensory tests were conducted under white light in each booth.

The soft drinks formulated with the two extracts obtained in the present study were compared with those of a control formulation containing the commercial colorant E163. Samples were presented to the panellists in coded clear plastic cups containing $20 \mathrm{~mL}$ of each formulation. Panellists were asked to cleanse their palate before the first sample and between samples using water and crackers. After training the following list of sensory attributes was generated and confirmed by the panel: colour intensity, cloudiness, sweetness, fruitiness, bitterness 
and sourness. A quantitative descriptive analysis (QDA) test was designed using the Compusense Cloud software (Compusense, Guelph, ON, Canada). The intensity of perception was scored for each attribute on a scale ranging from 1 (very low) to 9 (very high). Following the QDA questionnaire the panellists were asked to comment on the overall acceptability of each product based on their hedonic experience and indicate their preference among the three products.

\subsection{Statistical analysis}

Three samples were used for each assay, and all assays were carried out in triplicate. The results were analysed using the one-way analysis of variance (ANOVA) followed by Tukey's HSD Test $(\mathrm{p}=0.05)$. All data are expressed as mean values and standard deviation (SD). When less than three results were present in each individual analysis, $t$-Student test was used to determine the significant difference $(p=0.05)$. The sensory results were analysed using a two-way analysis of variance (ANOVA) followed by a Tukey's post-hoc Honest Significant Difference (HSD) test using the Compusense Cloud software $(p=0.05)$.

\section{Results and discussion}

\subsection{Aqueous extracts}

\subsubsection{Composition of anthocyanins}

The anthocyanins' profile, chromatographic characteristics, tentative identifications, and quantification of the seven aqueous extracts are shown in Table 1. All tentatively identified compounds were previously described in the literature for red and purple-fleshed potatoes (Alcalde-Eon, Saavedra, de Pascual-Teresa, \& Rivas-Gonzalo, 2004; Kita, Bąkowska-Barczak, Hamouz, Kułakowska, \& Lisińska, 2013; Oertel et al., 2017).

Seven peaks were detected in the red-fleshed varieties, six of which were identified as pelargonidin derivatives, based on the observation of their characteristic fragments in $\mathrm{MS}^{2}$ spectra. Peak $1 \mathrm{r}\left([\mathrm{M}]^{+}\right.$at $\left.m / z 741\right)$ was identified as pelargonidin-3-O-rutinoside-5-O-glucoside based on the HPLC-DAD-MS results and previous literature reports (Kita et al., 2013; Oertel et al., 2017), and was the major anthocyanin detected in the Red Cardinal extract. Peak 2r ([M] ${ }^{+}$at $m / z$ 579) also showed an $\mathrm{MS}^{2}$ fragment at $m / z 271$, corresponding to pelargonidin, bearing the loss of a hexose moiety $(-162 \mathrm{u})$ and being assigned as pelargonidin-3-Orutinoside. The remaining peaks were identified as acylated anthocyanins owing to the presence of a shoulder in the UV spectra of the compounds around $310-330 \mathrm{~nm}$. Peaks 3r, 4r, 5r, 6r, and $7 \mathbf{r}$ were identified

Table 1

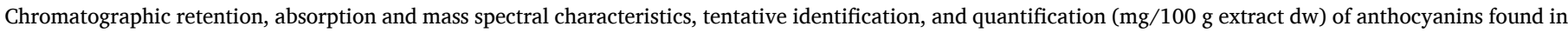
aqueous extracts from red and purple potato varieties (mean \pm SD).

\begin{tabular}{|c|c|c|c|c|c|c|c|c|c|}
\hline \multicolumn{9}{|c|}{ Red flesh } & \\
\hline Peak & $\begin{array}{l}\text { Rt } \\
(\min )\end{array}$ & $\lambda_{\max }(\mathrm{nm})$ & $\begin{array}{l}{[\mathrm{M}]^{+}(\mathrm{m} /} \\
z)\end{array}$ & $\operatorname{MS}^{2}(m / z)$ & Tentative identification & Rosemary & $\begin{array}{l}\text { Red } \\
\text { Emmalie }\end{array}$ & Red Cardinal & \\
\hline $1 \mathrm{r}$ & 8.27 & 499 & 741 & $\begin{array}{l}579(100), 433 \\
(15), 271(45)\end{array}$ & Pelargonidin-3-O-rutinoside-5-O-glucoside & $130 \pm 1^{c}$ & $171 \pm 1^{\mathrm{b}}$ & \multicolumn{2}{|l|}{$264 \pm 1^{\mathrm{a}}$} \\
\hline $2 \mathrm{r}$ & 20 & 501 & 579 & $\begin{array}{l}433(100), 271 \\
(46\end{array}$ & Pelargonidin-3-O-rutinoside & $109 \pm 1^{\mathrm{c}}$ & $\begin{array}{l}127.9 \pm \\
0.4^{\mathrm{b}}\end{array}$ & \multicolumn{2}{|l|}{$206.1 \pm 0.1^{\mathrm{a}}$} \\
\hline $3 r$ & 28.08 & 500 & 887 & $\begin{array}{l}725(100), 433 \\
(5), 271(16)\end{array}$ & $\begin{array}{l}\text { Pelargonidin-3-O-p-coumaroylrutinoside- } O \text { - } \\
\text { glucoside isomer }\end{array}$ & $\begin{array}{l}106.983 \pm \\
0.003^{c}\end{array}$ & $116 \pm 1^{\mathrm{b}}$ & \multicolumn{2}{|l|}{$214 \pm 1^{\mathrm{a}}$} \\
\hline $4 \mathrm{r}$ & 29.86 & 505 & 903 & $\begin{array}{l}741(100), 433 \\
(16), 271(27)\end{array}$ & $\begin{array}{l}\text { Pelargonidin-3-O-caffeoylrutinoside-5-O- } \\
\text { glucoside }\end{array}$ & $109.7 \pm 0.1$ & nd & \multicolumn{2}{|l|}{ nd } \\
\hline $5 r$ & 35.34 & 504 & 887 & $\begin{array}{l}725(100), 433 \\
(10), 271(13)\end{array}$ & $\begin{array}{l}\text { Pelargonidin-3-O-p-coumaroylrutinoside-5- } \\
O \text {-glucoside }\end{array}$ & $235 \pm 1^{*}$ & $332 \pm 1^{*}$ & \multicolumn{2}{|l|}{ nd } \\
\hline $6 r$ & 35.54 & 507 & 917 & $\begin{array}{l}755(100), 433 \\
(21), 271(41)\end{array}$ & $\begin{array}{l}\text { Pelargonidin-3-O-p-feruloylrutinoside-5-O- } \\
\text { glucoside isomer }\end{array}$ & nd & nd & \multicolumn{2}{|l|}{$202 \pm 1$} \\
\hline \multirow[t]{2}{*}{$7 \mathrm{r}$} & 36.48 & 506 & 917 & $\begin{array}{l}755(100), 463 \\
(15), 271(38)\end{array}$ & $\begin{array}{l}\text { Pelargonidin-3-O-p-feruloylrutinoside-5-O- } \\
\text { glucoside }\end{array}$ & $123.8 \pm 0.3^{\mathrm{c}}$ & $\begin{array}{l}128.9 \pm \\
0.4^{\mathrm{b}}\end{array}$ & \multicolumn{2}{|l|}{$202 \pm 1^{\mathrm{a}}$} \\
\hline & & & & & Total anthocyanin content & $815 \pm 2^{c}$ & $\begin{array}{l}875.6 \pm \\
0.3^{b}\end{array}$ & \multicolumn{2}{|l|}{$886 \pm 2^{a}$} \\
\hline \multicolumn{5}{|c|}{ Purple flesh } & & & & \multirow{2}{*}{\multicolumn{2}{|c|}{$\begin{array}{l}\text { Marble } \\
\text { flesh } \\
\text { Shetland } \\
\text { Black }\end{array}$}} \\
\hline Peak & $\begin{array}{l}\mathrm{Rt} \\
(\min )\end{array}$ & $\lambda_{\max }(\mathrm{nm})$ & $\begin{array}{l}{[\mathrm{M}]^{+}(m /} \\
z)\end{array}$ & $\operatorname{MS}^{2}(m / z)$ & Tentative identification & Purple & Violetta & & \\
\hline $1 \mathrm{p}$ & 7.46 & 530 & 787 & $\begin{array}{l}479(100), 317 \\
(15)\end{array}$ & Petunidin-3-O-rutinoside-5-O-glucoside & $134.3 \pm 0.1^{\mathrm{a}}$ & $\begin{array}{l}50.57 \pm \\
0.01^{\mathrm{c}}\end{array}$ & $113.2 \pm 0.2^{\mathrm{b}}$ & $125.9 \pm 0.2$ \\
\hline $2 \mathrm{p}$ & 10.04 & 515 & 771 & $\begin{array}{l}479(100), 317 \\
(16)\end{array}$ & $\begin{array}{l}\text { Petunidin- } O \text {-rutinoside- } O \text {-rhamnoside or } \\
\text { petunidin- } O \text {-dirhamnoside- } O \text {-glucoside }\end{array}$ & nd & $43 \pm 1$ & nd & $113 \pm 1$ \\
\hline $3 p$ & 25.34 & 525 & 933 & $\begin{array}{l}625(100), 479 \\
(23), 317(37)\end{array}$ & Positional isomer of peak $5 p$ & nd & $\begin{array}{l}43.1 \pm \\
0.4^{*}\end{array}$ & $104.5 \pm 0.2^{*}$ & $102 \pm 0.1$ \\
\hline $4 \mathrm{p}$ & 27.66 & 529 & 949 & $\begin{array}{l}625(100), 479 \\
(34), 317(46)\end{array}$ & $\begin{array}{l}\text { Petunidin-3-O-caffeoylrutinoside-5-O- } \\
\text { glucoside }\end{array}$ & nd & $46 \pm 1^{*}$ & $106.5 \pm 0.1 *$ & $102.0 \pm 0.2$ \\
\hline $5 p$ & 33.3 & 530 & 933 & $\begin{array}{l}771(100), 479 \\
(18), 317(22)\end{array}$ & $\begin{array}{l}\text { Petunidin-3-O-p-coumaroylrutinoside-5- } O \text { - } \\
\text { glucoside }\end{array}$ & $112.3 \pm 0.1^{c}$ & $175 \pm 2^{b}$ & $208 \pm 3^{\mathrm{a}}$ & $158.2 \pm 0.3$ \\
\hline $6 \mathrm{p}$ & 34.69 & 531 & 963 & $\begin{array}{l}625(100), 479 \\
(10), 317(30)\end{array}$ & $\begin{array}{l}\text { Petunidin-3-O-feruloylrutinoside-5-O- } \\
\text { glucoside }\end{array}$ & $101.6 \pm 0.2^{\mathrm{b}}$ & $\begin{array}{l}51.7 \pm \\
0.3^{\mathrm{c}}\end{array}$ & $113 \pm 1^{\mathrm{a}}$ & $104.1 \pm 0.2$ \\
\hline $7 p$ & 36.44 & 524 & 947 & $\begin{array}{l}785(100), 463 \\
(23), 301(38)\end{array}$ & $\begin{array}{l}\text { Peonidin-3-O-feruloylrutinoside-5- } O \text { - } \\
\text { glucoside }\end{array}$ & $130 \pm 1^{\mathrm{a}}$ & $\begin{array}{l}64.3 \pm \\
0.6^{\mathrm{c}}\end{array}$ & $106.8 \pm 0.2^{\mathrm{b}}$ & $117 \pm 1$ \\
\hline \multirow[t]{2}{*}{$8 \mathrm{p}$} & 39.13 & 529 & 771 & $\begin{array}{l}625(100), 479 \\
(14), 317(26)\end{array}$ & Petunidin-3-O-p-coumaroylrutinoside & nd & $40.3 \pm 0.1$ & nd & nd \\
\hline & & & & & Total anthocyanin content & $478 \pm 1^{c}$ & $513 \pm 4^{b}$ & $533 \pm 3^{\mathrm{a}}$ & $481 \pm 1$ \\
\hline
\end{tabular}

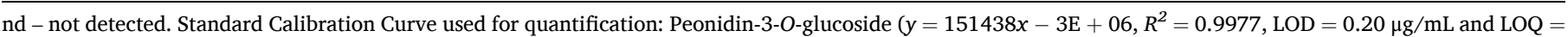

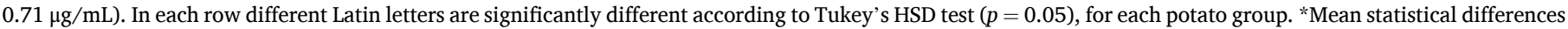
obtained by $t$-Student test. 
as acylated pelargonidin glycosides. Pelargonidin-3-O-p-coumaroylrutinoside-5-O-glucoside (Peak 5 r) was the main compound detected in the Red Emmalie and Rosemary extracts. Peak 3r, with the same molecular ion, might correspond to an isomer of peak $5 r$ having the glucoside residue located at position 7 , which is expected to elute earlier than the corresponding 5-O-glucoside, as reported by Alcalde-Eon et al. (2004) for similar petunidin isomers in Solanum stenotomum tubers. In agreement with our findings, acylated pelargonidin glycosides have been previously identified by other authors as the main pigments in red potato tubers (Kita et al., 2013; Lewis, Walker, Lancaster, \& Sutton, 1998; Oertel et al., 2017; Rodriguez-Saona et al., 1999).

All three red-fleshed varieties showed similar total anthocyanin content, and the Red Cardinal variety presented the highest value (886.2 $\pm 1.9 \mathrm{mg} / 100 \mathrm{~g}$ extract). Considering the extraction yield of $5 \%$ (mass of freeze-dried extract/mass of whole fresh potato), our results are in agreement with those found by Kita et al. (2013) for red-fleshed potato tubers. Moreover, Hamouz et al. (2011) also reported significant differences in total anthocyanin content among red- and purple-fleshed potato cultivars.

Regarding the purple-fleshed varieties, eight peaks were detected, seven of which were tentatively identified as petunidin derivatives (Peaks 1p - 6p and 8p) and one compound as an acylated peonidin glycoside (Peak $7 \mathbf{p}$ ). The molecular ions and fragmentation patterns of peaks $4 p$ to $6 p$ were coherent with derivatives of petunidin-3-O-rutinoside-5-O-glucoside acylated with caffeic, $p$-coumaric and ferulic acids, respectively, and peak $\mathbf{8 p}$ with petunidin-3-p-coumaroylrutinoside, all of them previously identified in purple tubers of Solanum tuberosum (Kita et al., 2013) and S. stenotomum (Alcalde-Eon et al., 2004). Similarly, the characteristics of peak $7 \mathbf{p}$ coincide with those of peonidin-3-O-feruloylrutinoside-5-O-glucoside described in purple tubers of S. stenotomum (Alcalde-Eon et al., 2004). Peak 3p possessed the same molecular ion $[\mathrm{M}]^{+}$at $\mathrm{m} / z 933$ as peak $\mathbf{5 p}$, but a different fragmentation pattern. Two compounds with this molecular ion were also reported by Alcalde-Eon et al. (2004) in purple tubers of S. stenotomum that were respectively identified as petunidin-3-O-p-coumaroylrutinoside-7-O-glucoside and petunidin-3-O- $p$-coumaroylrutinoside-5-glucoside, although in that case both compounds showed similar $\mathrm{MS}^{2}$ fragmentation. In the present study, peak $3 \mathbf{p}$ produced a main fragment at $m / z 625$ from the loss of $308 \mathrm{u}$ that could correspond either to a coumaroylglucoside or a rutinosyl residue, and a second fragment at $m / z 479(-146 \mathrm{u})$ from the further loss of either a coumaroyl or a rhamnosyl residue. This fragmentation rather seems to suggest a compound where the coumaroyl would be located on a glucose moiety instead on the rhamnose moiety, e.g., petunidin-O-rutinoside-O- $p$-coumaroylglucoside or petunidin-O-p-coumaroylglucosylrhamnoside-glucoside. Since no definite identity could be assigned, this peak was just assigned as a positional isomer of peak $\mathbf{5 p}$. Finally, peaks $1 \mathbf{p}$ and $\mathbf{2 p}$ showed earlier retention times and their absorption spectra lacked a shoulder at $310-330 \mathrm{~nm}$ indicating that they were not acylated. Peak $1 \mathbf{p}$ was assigned as petunidin-3-O-rutinoside-5-O-glucoside, previously identified by Kita et al. (2013) and Lewis et al. (1998) in purple tubers of Solanum tuberosum. The MS ${ }^{2}$ fragmentation of peak 2 p produced ions at $m / z 479$ ( $-292 \mathrm{u}$; loss of two rhamnosyl residues) and 317 (-162 u; loss of a glucosyl residue), so that the compound could be assigned as petunidin-rutinoside-rhamnoside, or alternatively to petunidin-dirhamnoside-glucoside. Petunidin-3-O-p-coumaroylrutinoside-5-glucoside (Peak 5p) was the main anthocyanin found in the extracts obtained from Violetta, Kefermarkter Blaue and Shetland Black tubers. The same compound was reported by Lewis et al. (1998) and Kita et al. (2013) as the main anthocyanin in different varieties of purple potatoes, and by Alcalde-Eon et al. (2004) in purple tubers of $S$. stenotomum. In our study, among the four tested purple-fleshed genotypes, Kefermarkter Blaue showed the highest total anthocyanin content $(533.4 \pm 2.8 \mathrm{mg} / 100 \mathrm{~g}$ extract).

The variability in the anthocyanin content among the studied extracts could be mainly attributed to inherited differences of the potato genotypes, as all samples were subjected to the same environmental factors (growing conditions, planting location and climate), cultivation practices, processing and storage conditions. Oertel et al. (2017) reported a great diversity in polyphenol and anthocyanin profiles of red and purple-fleshed potatoes and suggested differences in the enzymatic reactions leading to the hydroxylation and methylation of B-ring of the precursor dihydroflavonols, resulting in the biosynthesis of diverse and species specific anthocyanin backbones. In the same context, ChavesSilva et al. (2018) attributed the differences in the genetic regulation of biosynthetic pathways through the involvement of different structural and regulatory genes, while Lachman et al. (2012) highlighted the effect of genotype on the anthocyanin content of colour-fleshed potatoes.

\subsubsection{Bioactive properties}

The in vitro antioxidant, antibacterial and antifungal properties of the red and purple aqueous extracts were also evaluated, and the results are presented in Table 2. Additionally, a hepatotoxicity assay was carried out to assess the safety of the extracts for incorporation into food formulations.

Several studies have demonstrated the antioxidant properties of red and purple potatoes, which have been linked to their high content of anthocyanins (Jayawardana et al., 2012; Kita et al., 2013; Nemś et al., 2015; Nemś \& Pęksa, 2018). Previous studies have reported positive results for in vitro antioxidant assays on coloured potatoes, namely the 2,2'-azino-bis(3-ethylbenzothiazoline-6-sulfonate) (ABTS), the 2,2diphenyl-1-picrylhydrazyl (DPPH) and the ferric reducing/antioxidant power (FRAP) assays. Herein, a cell-based in vitro assay (inhibition of production of TBAR substances) was applied to assess the antioxidant properties of the tested colour-fleshed potato tubers.

As presented in Table 2, all seven studied aqueous potato extracts were effective in diminishing the production of TBAR substances, which result from lipid peroxidation-induced breakdown. Among the studied varieties, the purple-fleshed cv. Violetta presented the highest antioxidant capacity, since it required the lowest concentration of extract to inhibit the lipid peroxidation process by $50 \%\left(\mathrm{IC}_{50}\right.$ value $=380 \mu \mathrm{g} / \mathrm{mL}$ ) compared to the control (Trolox, $\mathrm{IC}_{50}$ value $=139 \pm 5 \mu \mathrm{g} / \mathrm{mL}$ ). For the red-fleshed varieties, cv. Rosemary presented the best result ( IC $_{50}$ value $=417 \mu \mathrm{g} / \mathrm{mL}$ ).

In agreement with our findings, Kita et al. (2013) previously reported positive results for antioxidant activity assays carried out on fresh tubers of red and purple-fleshed potatoes, where for example the purple variety Salad Blue showed significant antioxidant activity (ABTS: $1.56 \pm 0.2$ $\mathrm{mM} / 100 \mathrm{~g} \mathrm{dw}$; DPPH: $0.65 \pm 0.3 \mathrm{mM} / 100 \mathrm{~g} \mathrm{dw}$; FRAP: $3.17 \pm 0.3 \mathrm{mM} /$ $100 \mathrm{~g} \mathrm{dw}$ ). Similarly, Nemś et al. (2015) reported a positive antioxidant

\section{Table 2}

In-vitro antioxidant and cytotoxicity activity $(\mu \mathrm{g} / \mathrm{mL})$ of aqueous extracts from red, purple and marble (yellow/purple) potato varieties (mean $\pm \mathrm{SD}$ ).

\begin{tabular}{lll}
\hline Potato varieties & $\begin{array}{l}\text { Antioxidant activity (TBARS) } \\
\mathrm{IC}_{50} \text { values }\end{array}$ & $\begin{array}{l}\text { Cytotoxicity (PLP2) } \\
\mathrm{GI}_{50} \text { values }\end{array}$ \\
\hline Red flesh & & \\
Rosemary & $417 \pm 5^{\mathrm{e}, \mathrm{f}}$ & $>400$ \\
Red Emmalie & $669 \pm 4^{\mathrm{a}}$ & $>400$ \\
$\begin{array}{l}\text { Red Cardinal } \\
\text { Purple flesh }\end{array}$ & $592 \pm 8^{\mathrm{b}}$ & $>400$ \\
$\begin{array}{l}\text { Purple } \\
\text { Violetta }\end{array}$ & $426 \pm 3^{\mathrm{e}}$ & $>400$ \\
Kefermarkter Blaue & $380 \pm 6^{\mathrm{f}}$ & $>400$ \\
Marble flesh & $485 \pm 2^{\mathrm{d}}$ & $>400$ \\
Shetland Black & $548 \pm 6^{\mathrm{c}}$ & $>400$
\end{tabular}

$\mathrm{IC}_{50}$ : extract concentration corresponding to $50 \%$ of antioxidant activity (against lipid peroxidation). $\mathrm{GI}_{50}$ : values correspond to the sample concentration achieving $50 \%$ of growth inhibition in liver primary culture PLP2; maximum tested concentration: $400 \mu \mathrm{g} / \mathrm{mL}$. Positive control: Trolox $\mathrm{IC}_{50}$ value $-139 \pm 5$ $\mu \mathrm{g} / \mathrm{mL}$ (TBARS); Ellipticine $\mathrm{GI}_{50}$ value $-3.2 \pm 0.7 \mu \mathrm{g} / \mathrm{mL}$ (PLP2). In each line different Latin letters are significantly different according to Tukey's HSD test ( $p$ $=0.05$ ). 
activity for snacks enriched with coloured potato flour obtained from the same Salad Blue variety, employing in vitro assays (ABTS: $1.16 \pm$ $0.07 \mu \mathrm{mol}$ Trolox/g dw; DPPH: $0.60 \pm 0.06 \mu \mathrm{mol} \mathrm{Trolox} / \mathrm{g} \mathrm{dw}$; FRAP: $0.80 \pm 0.07 \mu \mathrm{mol}$ Trolox/g dw). Nemś and Pęksa (2018), who also incorporated dried coloured-fleshed potatoes into snacks, reported a beneficial effect on the inhibition of oxidative changes in the lipid profile compared to a control formulation over a 3-months storage period. Moreover, in a study conducted by Jayawardana et al. (2012), the addition of $2 \%$ coloured potato flakes into pork sausages suppressed lipid oxidation by $80 \%$ compared to the control. Thereby, the antioxidant properties of coloured potatoes could also have a beneficial effect in processed food products by extending their shelf-life.

In order to assess the safety of the studied extracts, an in vitro cytotoxicity assay was performed. Porcine liver was used as a model, which is justified by its similarity with the human liver in terms of cellular and physiological functioning (Corrêa et al., 2018). The results revealed that all seven aqueous extracts did not present toxicity against the porcine liver primary culture PLP2, as their $\mathrm{GI}_{50}$ values were higher than the highest tested concentration for all varieties $(400 \mu \mathrm{g} / \mathrm{mL}$ ) (Table 2$)$. The verified absence of cytotoxicity suggests the safety of the tested extracts for their utilisation as natural colourants in food products.

The results for antibacterial and antifungal activities are presented in Table 3. All seven extracts presented relevant antibacterial and antifungal activities against all the tested bacteria and fungi strains. Cultivar Red Cardinal performed particularly well against specific bacteria, as the required MIC value of the extract against Staphylococcus aureus (2 mg/ $\mathrm{mL}$ ) was half the MIC value required by the commercial preservative E211, sodium benzoate $(4 \mathrm{mg} / \mathrm{mL}$ ). The same variety also performed better than the control preservative E224 (potassium metabisulfite) against Bacillus cereus, as it required half of the MIC and MBC values for this bacterium strain.

All seven aqueous extracts behaved equally or better than the control preservatives E211 and E224 for all the tested fungi strains. The best results against fungi were achieved by the extract from the Kefermarkter Blaue variety, as its antifungal capacity exceeded both commercial preservatives for all the tested strains. The obtained results of the antimicrobial properties indicate that all the studied extracts could be useful in retarding and/or suppressing the growth of food borne microbes, which make them suitable candidates for application in food products as natural preservatives.

Previous studies by other authors also reported positive antimicrobial activities from coloured potato extracts. For instance, Ombra et al. (2015) studied the purple-fleshed variety Vitelotte Noire, and found that its anthocyanin-rich extract was effective against the bacteria strains Escherichia coli, Pseudomonas aeruginosa and Bacillus cereus. Interestingly, those authors also found that the natural bioactive compounds from purple potatoes retained their biological activity (antimicrobial, antioxidant and anti-proliferative) during their passage through the gastrointestinal tract, suggesting that the consumption of these nutrient components could be beneficial in terms of disease prevention. Similar results were reported by Bontempo et al. (2013), who tested the purplefleshed variety Vitelotte and observed significant activities against Staphylococcus aureus and Rhizoctonia solani.

\subsection{Application of the extracts in soft drink formulations}

Following the screening of the seven potato varieties on their anthocyanin profiles and bioactivities, two aqueous extracts were selected to be incorporated as natural colourants into soft drink formulations, namely one from the red-fleshed variety Rosemary and one from the purple-fleshed variety Purple. The two soft drink formulations were assessed for their sensorial attributes and stability after thermal processing (pasteurisation), in comparison with the Control colourant E163.

\subsubsection{Colour stability assessment}

The results for the colour parameters $L^{*}$ (lightness), $a^{*}$ (greenredness), $b^{*}$ (blue-yellowness), $\mathrm{C}^{*}$ (chroma/saturation) and $\mathrm{h}^{\circ}$ (hue) measured over time (after pasteurisation) are presented in Fig. 2.

At Day 0, the control soft drink showed a slight distinct colouration when compared to Rosemary and Purple treatments, presenting lower $a^{*}$ and higher $b^{*}$ values, which means a more intense presence of blue tones

Table 3

Antibacterial and antifungal activities $(\mathrm{mg} / \mathrm{mL})$ of aqueous extracts from red, purple and marble-fleshed potato varieties.

\begin{tabular}{|c|c|c|c|c|c|c|c|c|c|c|c|c|c|c|}
\hline \multirow[t]{2}{*}{ Potato Variety } & \multicolumn{7}{|c|}{ Bacteria } & \multicolumn{7}{|l|}{ Fungi } \\
\hline & & S.a. & B.c. & L.m. & E.c. & S.t. & E.c. & & A.f & A.n. & A.v. & P.f. & P.v.c. & T.v. \\
\hline \multicolumn{15}{|l|}{ Red flesh } \\
\hline \multirow[t]{2}{*}{ Rosemary } & MIC & 4 & 2 & 3 & 3 & 4 & 3 & MIC & 0.5 & 0.5 & 0.5 & 0.35 & 0.5 & 0.25 \\
\hline & MBC & 8 & 4 & 4 & 4 & 8 & 4 & MFC & 1 & 1 & 1 & 0.5 & 1 & 0.5 \\
\hline \multirow[t]{2}{*}{ Red Emmalie } & MIC & 2 & 1.5 & 2 & 3 & 3 & 3 & MIC & 0.5 & 0.5 & 0.5 & 0.5 & 1 & 0.35 \\
\hline & MBC & 4 & 2 & 4 & 4 & 4 & 4 & MFC & 1 & 1 & 1 & 1 & 2 & 0.5 \\
\hline \multirow[t]{2}{*}{ Red Cardinal } & MIC & 2 & 1 & 2 & 1.5 & 3 & 3 & MIC & 1 & 0.5 & 1 & 0.5 & 0.5 & 0.25 \\
\hline & MBC & 4 & 2 & 4 & 2 & 4 & 4 & MFC & 2 & 1 & 2 & 1 & 1 & 0.5 \\
\hline \multicolumn{15}{|l|}{ Purple flesh } \\
\hline \multirow[t]{2}{*}{ Purple } & MIC & 3 & 1 & 3 & 1.5 & 3 & 3 & MIC & 0.5 & 0.5 & 0.5 & 0.5 & 0.5 & 1 \\
\hline & MBC & 4 & 2 & 4 & 2 & 4 & 4 & MFC & 1 & 1 & 1 & 1 & 1 & 2 \\
\hline \multirow[t]{2}{*}{ Violetta } & MIC & 3 & 1 & 3 & 1.5 & 3 & 3 & MIC & 0.25 & 0.125 & 1 & 0.25 & 0.5 & 0.125 \\
\hline & MBC & 4 & 2 & 4 & 2 & 4 & 4 & MFC & 0.5 & 0.25 & 2 & 0.5 & 1 & 0.25 \\
\hline \multirow[t]{2}{*}{ Kefermarkter Blaue } & MIC & 6 & 3 & 3 & 3 & 6 & 6 & MIC & 0.25 & 0.125 & 0.35 & 0.25 & 0.5 & 0.125 \\
\hline & MBC & 8 & 4 & 4 & 4 & 8 & 8 & MFC & 0.5 & 0.25 & 0.5 & 0.5 & 1 & 0.25 \\
\hline \multicolumn{15}{|l|}{ Marble flesh } \\
\hline \multirow[t]{2}{*}{ Shetland Black } & MIC & 4 & 1 & 3 & 1 & 4 & 4 & MIC & 1 & 0.5 & 0.5 & 0.75 & 0.5 & 0.25 \\
\hline & MBC & 8 & 2 & 4 & 2 & 8 & 8 & MFC & 2 & 1 & 1 & 1 & 1 & 0.5 \\
\hline \multicolumn{15}{|l|}{ Controls } \\
\hline \multirow[t]{2}{*}{ E211 } & MIC & 4.0 & 0.5 & 1.0 & 1.0 & 1.0 & 2.0 & MIC & 1.0 & 1.0 & 2.0 & 1.0 & 2.0 & 1.0 \\
\hline & MBC & 4.0 & 0.5 & 2.0 & 2.0 & 2.0 & 4.0 & MFC & 2.0 & 2.0 & 2.0 & 2.0 & 4.0 & 2.0 \\
\hline \multirow[t]{2}{*}{ E224 } & MIC & 1.0 & 2.0 & 0.5 & 0.5 & 1.0 & 0.5 & MIC & 1.0 & 1.0 & 1.0 & 0.5 & 1.0 & 0.5 \\
\hline & MBC & 1.0 & 4.0 & 1.0 & 1.0 & 1.0 & 0.5 & MFC & 1.0 & 1.0 & 1.0 & 0.5 & 1.0 & 0.5 \\
\hline
\end{tabular}

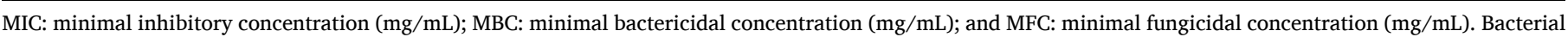

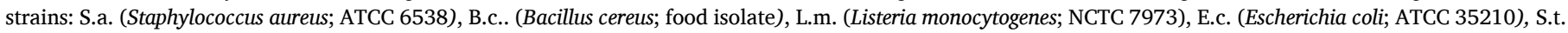

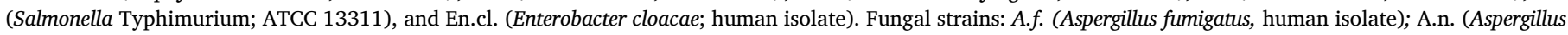

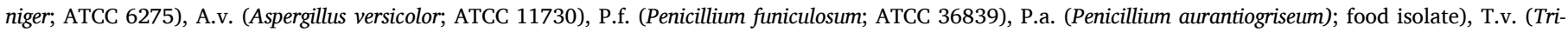
choderma viride; IAM 5061). Positive controls: E211- sodium benzoate and E224 - potassium metabisulphite. 


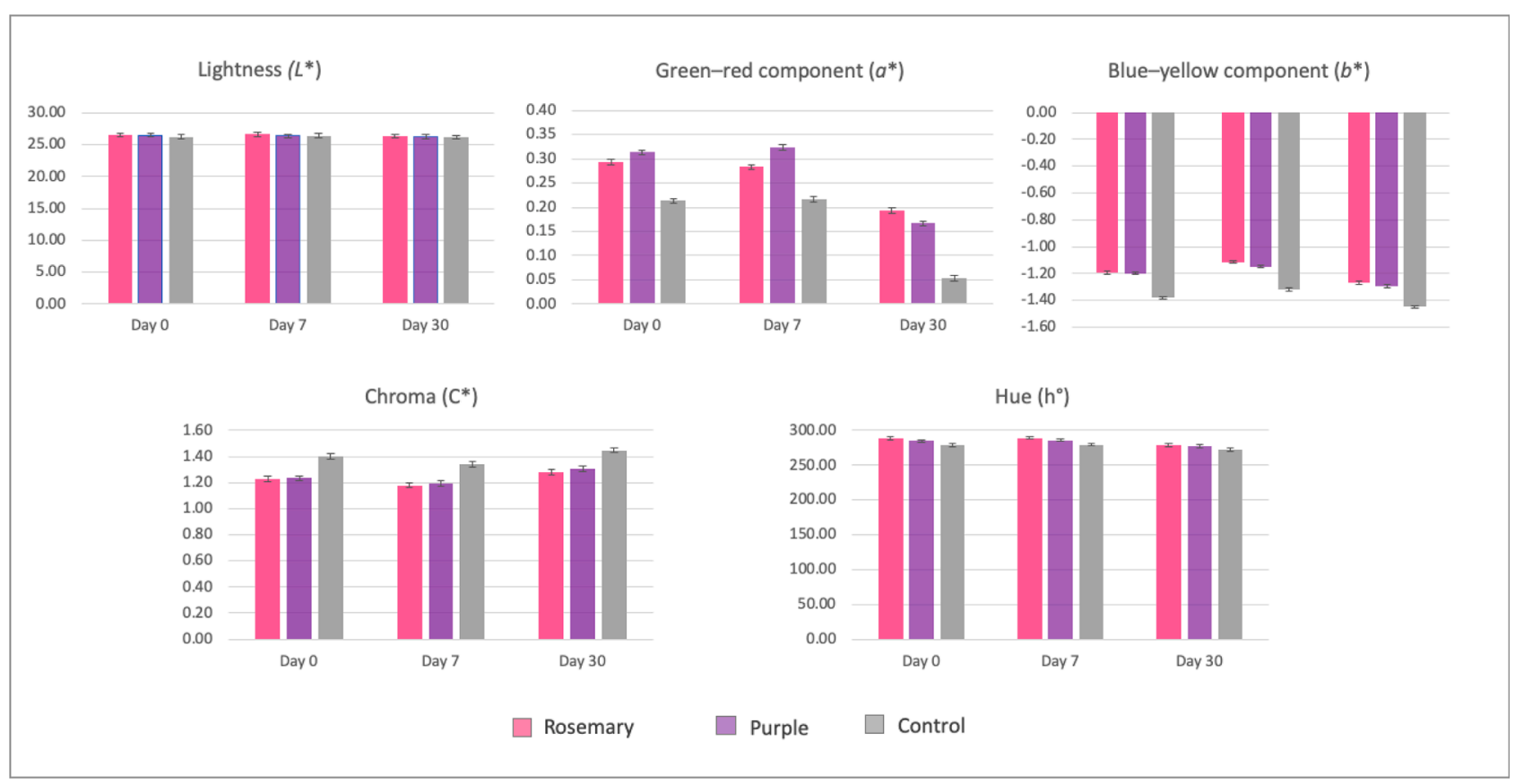

Fig. 2. CIELab colour values ( $L^{*}, a^{*}$ and $\left.b^{*}\right)$ and cylindrical coordinates $\left(\mathrm{C}^{*}\right.$ and $\mathrm{h}^{\circ}$ ) of the soft drink formulations Rosemary (red potato extract), Purple (purple potato extract) and Control (E163 commercial colouring), over a 30 days shelf-life period. $L^{*}$ : lightness from black $(0)$ to white $(100)$; $a^{*}$ : green $(-)$ to red $(+), b^{*}:$ blue $(-)$ to yellow ( + ); $\mathrm{C}^{*}$ : chroma, relative saturation; and $\mathrm{h}^{\circ}$ : angle of the hue in the CIELab colour space. (For interpretation of the references to colour in this figure legend, the reader is referred to the web version of this article.)

and less intensity of red ones. Despite all three formulations having the same concentration of anthocyanins, this difference in colour tone and intensity may be due to the distinct anthocyanin glycosides present in the two tested colouring agents (Table 1) and in the control E163 (grape anthocyanins). It should be noted that the colour profile of the three samples presented a great stability between Day 0 and Day 7 for all the analysed parameters. At Day 30 a significant decrease in $a^{*}$ values was recorded for all the tested formulations, which could be related to a reduction in the intensity of the red colour. A strong positive correlation between the total anthocyanins content and the chroma parameters in purple-fleshed sweet potatoes was also observed by Loypimai, Moongngarm, and Chottanom (2016). According to Ashurst (2011), in a comprehensive report on the stability and shelf life of fruit juices and soft drinks, product discoloration is a process commonly observed in almost any soft drink or fruit juice. This can be explained by a decrease in the concentration of the original anthocyanins as a result of their degradation and/or transformation in newly-formed derived pigments (Santos-Buelga \& González-Paramás, 2019). The degradation of anthocyanins over time was also reported by Jie et al. (2013) and Loypimai et al. (2016) in purple-fleshed sweet potato and black rice extracts, respectively. Similarly, anthocyanin decay and the discoloration process was observed by Rodriguez-Saona et al. (1998) when monitoring the anthocyanin stability of frozen red-fleshed potato tubers over storage of a three month-period. Those authors attributed the observed anthocyanin content decay to possible enzymatic reactions.

According to the results herein obtained, the performances of the aqueous potato extracts over shelf-life could be considered satisfactory, as they were similar to the control commercial colourant (a grape extract containing potassium sorbate as preservative). This performance might be explained by the presence of acylated anthocyanins in potatoes. The acylation confers increased biochemical stability to anthocyanin forms, preventing their indiscriminate degradation by glycosidases, most of which are unable to act on acylated glycosides (Mateus \& Freitas, 2009). Therefore, our results indicate the suitability of the red and purple potato aqueous extracts to be used as alternative natural colouring agents in beverages.

\subsubsection{Sensory analysis}

The scores obtained in the sensory analysis are shown in Fig. 3. The Rosemary, Purple and Control formulations were assessed by the 12 trained panellists for the following attributes: intensity of colour, cloudiness, sweetness, fruitiness, bitterness and sourness.

Regarding visual attributes, no statistical difference was reported between the Control formulation and Rosemary for intensity of colour and cloudiness. Purple, however, presented a significantly cloudier solution and a significantly lighter colour than both Rosemary and Control ( $\mathrm{p}<0.05$ ). Rosemary and Control formulations were described by the panellists as presenting a light transparent pink colour while Purple was described as presenting a slightly opaque light pink colour.

No statistical difference was reported between the three formulations for the tested flavour attributes sweetness, fruitiness and bitterness. With regard to sourness, Control was rated significantly higher than Rosemary ( $\mathrm{p}<0.05$ ). Nevertheless, no significant difference was found between Purple and Rosemary and between Purple and Control for this attribute. Additionally, no off-odours or off-tastes were detected in any of the tested formulations.

At the end of the evaluation session the 12 panellists were asked to choose their preferred formulation among the three ones tested. The soft drinks formulated with Rosemary and Purple extracts performed well, with $42 \%$ of the panellists choosing Purple and $25 \%$ choosing Rosemary as their preferred one, while $33 \%$ preferred the Control soft drink. Interestingly, some panellists highlighted in their comments the opaqueness described in Purple as a positive attribute, relating it to a "natural rather than synthetic appearance".

The presented results regarding the sensorial analysis and the stability over time of the red and purple-fleshed potato formulations indicate promising potential for their future application in the food industry as substitutes of synthetic colouring agents.

\section{Conclusion}

The seven aqueous potato extracts tested presented high anthocyanin content and high antioxidant, antibacterial and antifungal 


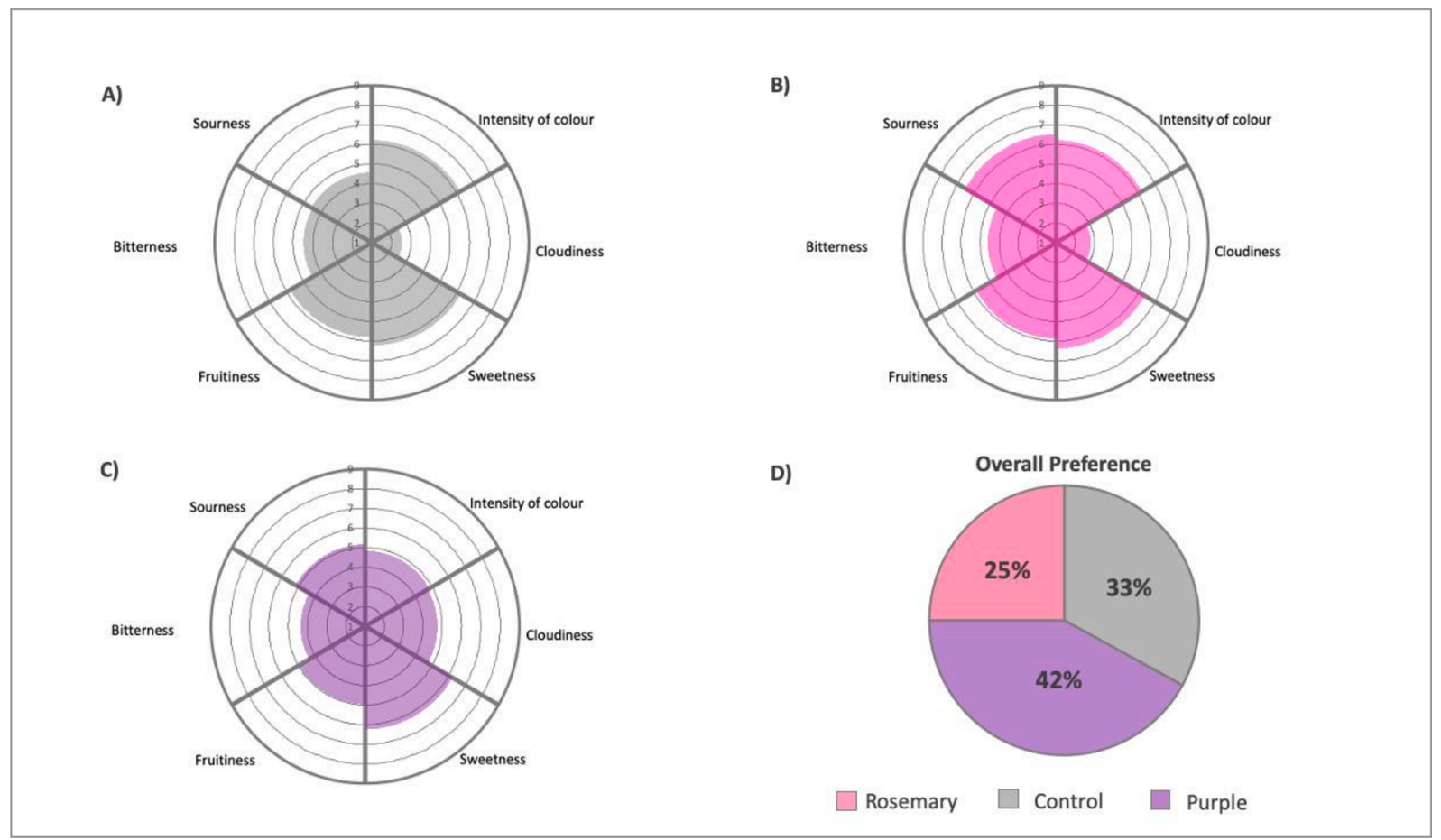

Fig. 3. Sensory analysis scores ( 1 to 9 ) for the attributes: intensity of colour, cloudiness, sweetness, fruitiness, bitterness and sourness, and overall preference of the tested soft drink formulations. A) Rosemary potato extract; B) Control E163; C) Purple potato extract; D) overall preference scores. (For interpretation of the references to colour in this figure legend, the reader is referred to the web version of this article.)

properties. Acylated pelargonidin glycosides were the main compounds found in the red varieties and acylated petunidin glycosides in the purple ones. Additionally, no cytotoxic effect was detected in the extracts up to the maximum tested concentration $(400 \mu \mathrm{g} / \mathrm{mL})$, indicating their safety to be incorporated in food formulations and substitute the existing synthetic colouring agents. The two extracts selected to be applied in a soft drink formulation showed suitable profiles in the sensory and shelf-life assessments when compared with the control commercial colourant E163. The aqueous extracts herein obtained by a simple one-step and cost-effective extraction method could be used as alternative natural food colourants, substituting synthetic compounds and satisfying the current market needs and consumer preferences for natural products. Nevertheless, future studies in pre- and post-harvest level could support the selection of colour-fleshed potatoes with high anthocyanin content. Furthermore, the assessment of different agronomic practices may increase the concentration of anthocyanins and the added value of this important vegetable crop.

\section{CRediT authorship contribution statement}

Shirley L. Sampaio: Methodology, Investigation, Formal analysis, Writing - original draft. Julien Lonchamp: Methodology, Investigation. M.I. Dias: Methodology, Investigation, Writing - original draft. Catriona Liddle: Methodology, Investigation. Spyridon A. Petropoulos: Methodology, Investigation, Writing - original draft. Jasmina Glamočlija: Investigation, Methodology. Alexios Alexopoulos: Investigation, Writing - review \& editing. Celestino Santos-Buelga: Validation, Writing - review \& editing. I.C.F.R. Ferreira: Conceptualization, Validation, Writing - review \& editing. L. Barros: Conceptualization, Supervision, Resources, Writing - review \& editing.

\section{Declaration of Competing Interest}

The authors declare that they have no known competing financial interests or personal relationships that could have appeared to influence the work reported in this paper.

\section{Acknowledgment}

S. Sampaio acknowledges CAPES Foundation (Ministry of Education, Brazil) for her PhD grant no. 99999.001423/2015-00. The authors are grateful to the Foundation for Science and Technology (FCT, Portugal) for financial support through national funds FCT/MCTES to CIMO (UIDB/00690/2020); the national funding by FCT, P.I., through the institutional scientific employment program-contract for L. Barros and Maria Inês Dias contracts; to FEDER-Interreg España-Portugal programme through the project 0377_Iberphenol_6_E and and TRANSCoLAB 0612_TRANS_CO_LAB_2_P, and also to the Ministry of Education, Science and Technological Development of Republic of Serbia (451-0368/2020-14/200007).

GIP-USAL is financially supported by the Spanish Government through the project AGL2015-64522-C2-2-R.

\section{References}

Albuquerque, B. R., Pinela, J., Barros, L., Oliveira, M. B. P. P., \& Ferreira, I. C. F. R. (2020). Anthocyanin-rich extract of jabuticaba epicarp as a natural colorant: Optimization of heat- and ultrasound-assisted extractions and application in a bakery product. Food Chemistry, 316, 126364. https://doi.org/10.1016/j. foodchem.2020.126364.

Alcalde-Eon, C., Saavedra, G., de Pascual-Teresa, S., \& Rivas-Gonzalo, J. C. (2004). Identification of anthocyanins of pinta boca (Solanum stenotomum) tubers. Food Chemistry, 86(3), 441-448. https://doi.org/10.1016/j.foodchem.2003.09.019.

Ashurst, P. (2011). In Food and Beverage Stability and Shelf Life (pp. 571-593). Elsevier. https://doi.org/10.1533/9780857092540.3.571.

Bontempo, P., Carafa, V., Grassi, R., Basile, A., Tenore, G. C., Formisano, C., ... Altucci, L. (2013). Antioxidant, antimicrobial and anti-proliferative activities of Solanum tuberosum L. var. Vitelotte. Food and Chemical Toxicology, 55, 304-312. https://doi. org/10.1016/j.fct.2012.12.048.

Bursać Kovačević, D., Putnik, P., Dragović-Uzelac, V., Vahčić, N., Babojelić, M. S., \& Levaj, B. (2015). Influences of organically and conventionally grown strawberry cultivars on anthocyanins content and color in purees and low-sugar jams. Food Chemistry, 181, 94-100. https://doi.org/10.1016/j.foodchem.2015.02.063.

Chaves-Silva, S., dos Santos, A. L., Chalfun-Júnior, A., Zhao, J., Peres, L. E. P., \& Benedito, V. A. (2018). Understanding the genetic regulation of anthocyanin 
biosynthesis in plants - Tools for breeding purple varieties of fruits and vegetables. Phytochemistry, 153(May), 11-27. https://doi.org/10.1016/j. phytochem.2018.05.013.

Corrêa, R. C. G., Barros, L., Fernandes, Â., Sokovic, M., Bracht, A., Peralta, R. M., \& Ferreira, I. C. F. R. (2018). A natural food ingredient based on ergosterol: Optimization of the extraction from Agaricus blazei , evaluation of bioactive properties and incorporation in yogurts. Food \& Function, 9(3), 1465-1474. https:// doi.org/10.1039/C7FO02007D.

Corrêa, R. C. G., de Souza, A. H. P., Calhelha, R. C., Barros, L., Glamoclija, J., Sokovic, M., ... Ferreira, I. C. F. R. (2015). Bioactive formulations prepared from fruiting bodies and submerged culture mycelia of the Brazilian edible mushroom Pleurotus ostreatoroseus Singer. Food \& Function, 6(7), 2155-2164. https://doi.org/10.1039/ C5FO00465A.

Da Silva, R. F. R., Barreira, J. C. M., Heleno, S. A., Barros, L., Calhelha, R. C., \& Ferreira, I. C. F. R. (2019a). Anthocyanin profile of elderberry juice: A natural-based bioactive colouring ingredient with potential food application. Molecules, 24(13), 1-13. https://doi.org/10.3390/molecules24132359.

Da Silva, L. P., Pereira, E., Prieto, M. A., Simal-Gandara, J., Pires, T. C. S. P., Alves, M. J., ... Ferreira, I. C. F. R. (2019b). Rubus ulmifolius Schott as a Novel Source of Food Colorant: Extraction optimization of coloring pigments and incorporation in a bakery product. Molecules, 24(11). https://doi.org/10.3390/molecules24112181.

Hamouz, K., Lachman, J., Pazderů, K., Tomášek, J., Hejtmánková, K., \& Pivec, V. (2011). Differences in anthocyanin content and antioxidant activity of potato tubers with different flesh colourDifferences in anthocyanin content and antioxidant activity of potato tubers with different flesh colour. Plant Soil Environment, 57(No. 10), 478-485. https://doi.org/10.17221/265/2011-PSE.

Hossain, M. B., Rawson, A., Aguiló-Aguayo, I., Brunton, N. P., \& Rai, D. K. (2015). Recovery of Steroidal Alkaloids from Potato Peels Using Pressurized Liquid Extraction. Molecules, 20, 8560-8573. https://doi.org/10.3390/ molecules 20058560.

Jayawardana, B. C., Yanagihara, M., Han, K.-H., Fukushima, M., Sekikawa, M., \& Shimada, K. (2012). Effects of Anthocyanin-rich Colored Potato Flakes on Lipid Oxidation, Instrumental Color Evaluation and Sensory Characteristics in Cooked Pork Sausages. Food Science and Technology Research, 18(3), 455-460. https://doi. org/10.3136/fstr.18.455.

Jie, L., Xiao-ding, L., Yun, Z., Zheng-dong, Z., Zhi-ya, Q., Meng, L., \& Lu, Q. (2013). Identification and thermal stability of purple-fleshed sweet potato anthocyanins in aqueous solutions with various $\mathrm{pH}$ values and fruit juices. Food Chemistry, 136, 1429-1434. https://doi.org/10.1016/j.foodchem.2012.09.054.

Kita, A., Bąkowska-Barczak, A., Hamouz, K., Kułakowska, K., \& Lisińska, G. (2013). The effect of frying on anthocyanin stability and antioxidant activity of crisps from redand purple-fleshed potatoes (Solanum tuberosum L.). Journal of Food Composition and Analysis, 32(2), 169-175. https://doi.org/10.1016/j.jfca.2013.09.006.

Lachman, J., Hamouz, K., Orsák, M., Pivec, V., Hejtmánková, K., Pazderů, K., ... Čepl, J. (2012). Impact of selected factors - Cultivar, storage, cooking and baking on the content of anthocyanins in coloured-flesh potatoes. Food Chemistry, 133(4), 1107-1116. https://doi.org/10.1016/j.foodchem.2011.07.077.

Lewis, C. E., Walker, J. R. L., Lancaster, J. E., \& Sutton, K. H. (1998). Determination of anthocyanins, flavonoids and phenolic acid in potatoes. I: Coloured cultivars of Solanum tuberosum L. Journal of the Science of Food and Agriculture, 77(1), 45-47.

Loypimai, P., Moongngarm, A., \& Chottanom, P. (2016). Thermal and pH degradation kinetics of anthocyanins in natural food colorant prepared from black rice bran. Journal of Food Science and Technology, 53(1), 461-470. https://doi.org/10.1007/ s13197-015-2002-1.

Mateus, N., \& Freitas, V. de. (2009). Anthocyanins as Food Colorants. Anthocyanins Biosynthesis, Functions and Applications. In C. Winefield, K. Davies, \& K. Gould (Eds.) New York, NY: Springer New York. https://doi.org/10.1007/978-0-387-77335-3.

Monteiro, M. J. P., Costa, A. I. A., Fliedel, G., Cissé, M., Bechoff, A., Pallet, D., Pintado, M. M. E. (2017). Chemical-sensory properties and consumer preference of hibiscus beverages produced by improved industrial processes. Food Chemistry, 225 202-212. https://doi.org/10.1016/j.foodchem.2016.11.127.

Montibeller, M. J., de Lima Monteiro, P., Tupuna-Yerovi, D. S., Rios, A.d. O., \& Manfroi, V. (2018). Stability assessment of anthocyanins obtained from skin grape applied in kefir and carbonated water as a natural colorant. Journal of Food Processing and Preservation, 42(8), e13698. https://doi.org/10.1111/jfpp.13698.
Nemś, A., \& Pęksa, A. (2018). Polyphenols of coloured-flesh potatoes as native antioxidants in stored fried snacks. LWT - Food Science and Technology, 97, 597-602. https://doi.org/10.1016/j.lwt.2018.07.053.

Nemś, A., Pęksa, A., Kucharska, A. Z., Sokół-Łętowska, A., Kita, A., Drożdż, W., \& Hamouz, K. (2015). Anthocyanin and antioxidant activity of snacks with coloured potato. Food Chemistry, 172, 175-182. https://doi.org/10.1016/j. foodchem.2014.09.033.

Oertel, A., Matros, A., Hartmann, A., Arapitsas, P., Dehmer, K. J., Martens, S., \& Mock, H.-P. (2017). Metabolite profiling of red and blue potatoes revealed cultivar and tissue specific patterns for anthocyanins and other polyphenols. Planta, 246(2), 281-297. https://doi.org/10.1007/s00425-017-2718-4.

Ombra, M. N., Fratianni, F., Granese, T., Cardinale, F., Cozzolino, A., \& Nazzaro, F. (2015). In vitro antioxidant, antimicrobial and anti-proliferative activities of purple potato extracts (Solanum tuberosum cv Vitelotte noire) following simulated gastrointestinal digestion. Natural Product Research, 29(11), 1087-1091. https://doi.org/ 10.1080/14786419.2014.981183.

Petropoulos, S. A., Fernandes, Â., Polyzos, N., Antoniadis, V., Barros, L., Ferreira, C. F. R., \& I. (2020). The Impact of fertilization regime on the crop performance and chemical composition of potato (Solanum tuberosum L.) cultivated in central Greece. Agronomy, 10(474), 1-18. https://doi.org/10.3390/agronomy10040474.

Petropoulos, S. A., Sampaio, S. L., Gioia, F. Di, Tzortzakis, N., Rouphael, Y., Kyriacou, M. C., \& Ferreira, I. (2019). Grown to be Blue - Antioxidant Properties and Health Effects of Colored Vegetables. Part I : Root Vegetables. Antioxidants, 8 (617), 1-26. https://doi.org/10.3390/antiox8120617.

Pires, T. C. S. P., Dias, M. I., Barros, L., Barreira, J. C. M., Santos-Buelga, C., \& Ferreira, I. C. F. R. (2018). Incorporation of natural colorants obtained from edible flowers in yogurts. LWT-Food Science \& Technology, 97(August), 668-675. https:// doi.org/10.1016/j.lwt.2018.08.013.

Quan, Wei, He, Wei, Lu, Mei, Yuan, Bo, Zeng, Maomao, Gao, Daming, ... He, Zhiyong (2019). Anthocyanin composition and storage degradation kinetics of anthocyaninsbased natural food colourant from purple-fleshed sweet potato. International Journal of Food Science \& Technology, 54(8), 2529-2539. https://doi.org/10.1111/ ijfs. 14163 .

Rodriguez-Saona, L. E., Giusti, M. M., \& Wrolstad, R. E. (1999). Color and Pigment Stability of Red Radish and Red-Fleshed Potato Anthocyanins in Juice Model Systems. J Food Science, 64(3), 451-456. https://doi.org/10.1111/j.13652621.1999.tb15061.x.

Rodriguez-Saona, L. E., Giusti, M. M., \& Wrolstad, R. E. (2008). Expanding the potato industry: Exotic-colored fleshed tubers. ACS Symposium Series, 983, 114-130. https://doi.org/10.1021/bk-2008-0983.ch009.

Rodriguez-Saona, Luis E., GiustiI, M. Monica, \& Wrolstad, Ronald E. (1998). Anthocyanin Pigment Composition of Red-fleshed Potatoes. J Food Science, 63(3), 458-465. https://doi.org/10.1111/j.1365-2621.1998.tb15764.x.

Sampaio, S. L., Fernandes, A., Pereira, C., Calhelha, R. C., Sokovic, M., Santos-Buelga, C., ... Ferreira, I. C. F. R. (2020a). Nutritional value, physicochemical characterization and bioactive properties of Brazilian quinoa BRS Piabiru. Food \& Function, 11, 2969-2977. https://doi.org/10.1039/d0fo00055h.

Sampaio, S. L., Petropoulos, S. A., Alexopoulos, A., Heleno, S. A., Santos-Buelga, C., Barros, L., \& Ferreira, I. C. F. R. (2020b). Potato peels as sources of functional compounds for the food industry: A review. Trends in Food Science \& Technology, 103, 118-129. https://doi.org/10.1016/j.tifs.2020.07.015.

Santos-Buelga, C., \& González-Paramás, A.M. (2019). In Melton, L., Shahidi, F., \& Varelis, P. (Eds.), Encyclopedia of Food Chemistry : 1 (pp. 10-21). Elsevier.

Sasaki, N., Nishizaki, Y., Ozeki, Y., \& Miyahara, T. (2014). The role of acyl-glucose in anthocyanin modifications. Molecules, 19(11), 18747-18766. https://doi.org/ 10.3390/molecules191118747.

Schieber, A., Stintzing, F. C., \& Carle, R. (2002). By-products of plant food processing as a source of functional compounds - recent developments. Trends in Food Science \& Technology, 12(2001), 401-413.

Stokstad, Erik (2019). The new potato. Science, 363(6427), 574-577. https://doi.org/ 10.1126/science:363.6427.574.

Wrolstad, R. E., \& Culver, C. A. (2012). Alternatives to Those Artificial FD\&C Food Colorants. Annual Review of Food Science and Technology, 3(1), 59-77. https://doi. org/10.1146/annurev-food-022811-101118. 